\title{
Atypical Presentation in Patients with Acute Coronary Syndrome
}

\author{
Hyun Kuk Kim and Myung Ho Jeong \\ The Heart Center of Chonnam National University Hospital, Gwangju, \\ Korea
}

\section{Introduction}

Chest pain has been reported as a cardinal clinical feature among the patients with acute coronary syndrome (ACS). However, several patients exhibit the atypical or no symptom on initial evaluation. Atypical symptom was defined as the absence of chest pain before or during admission, and may have included gastrointestinal or respiratory symptoms such as dyspnea, nausea, vomiting, and abdominal discomfort.

Patients who present without chest pain are frequently misdiagnosed, and less likely to receive optimal treatment for ACS. Consequently, greater in-hospital morbidity, and mortality are noted. Therefore, understanding the factor associated with atypical presentations may help in the earlier detection and treatments in patients with ACS.

Prior to discussing the risk factor, clarifying the concept of symptom in patients with ACS is needed to figure out this theme. In this manuscript, atypical presentation is used interchangeably 1 or $1+2$ in figure 1 according to each reference (Fig.1).

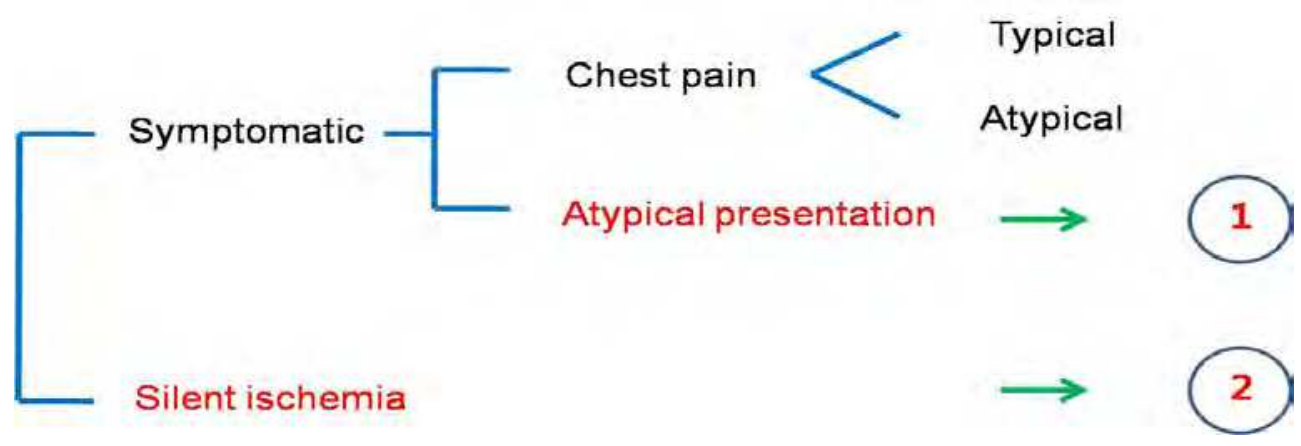

Fig. 1. Definition of atypical presentation; 1 or $1+2$ 


\section{Definition of clinical presentation}

\subsection{Ischemic chest pain}

There are several features that tend to distinguish ischemic chest pain from non-cardiac pain.

- Quality - patients with ischemic pain often describe more as a discomfort than pain. Typical pain is expressed by terms include squeezing, tightness, pressure, constriction, strangling, burning, heavy weight on chest. It is not generally described as sharp, knifelike, stabbing, and pins.

- Site - ischemic pain is a diffuse discomfort that may be difficult to localize. The sensation is often located in the retro-sternal area but may be felt in the epigastrium, back, arms, or jaw. Pain radiating to the upper extremities is highly suggestive of ischemic pain.

- Onset - ischemic pain is described as having a crescendo pattern (wax and wane), and is typically gradual in onset.

- Provocation and relieving factors - ischemic pain is usually developed by situations such as exercise, emotional stress which increases cardiac oxygen demands. Chest pain that is reproduced on respiration, coughing, position change, palpation is often associated with not-ACS disease. Relief of pain after administration of nitroglycerin or gastro-intestinal cocktails (GI cocktails; viscous lidocaine and antacid) could not guarantee the cardiac or gastric origin pain.

\subsection{Atypical chest pain and presentation}

The following characteristics were considered as more non-ischemic chest discomfort.

- Sharp or knife like pain related to respiration, coughing

- Reproduced pain by movement or palpation

- $\quad$ Localized pain with one finger

- Radiating pain into the lower extremities or above the mandible

- $\quad$ Pain lasting for days or a few seconds

Atypical presentation was defined as the absence of chest pain before or during admission, and may have included gastrointestinal or respiratory symptoms such as dyspnea, nausea, vomiting, and abdominal discomfort. The prevalence of this presentation was $8.4 \%$ in the Global Registry of Acute Coronary Events (GRACE), 33\% in the National Registry of Myocardial Infarction 2 (NRMI-2) and the dominant symptoms in these patients were dyspnea, nausea, syncope (Fig.2).

\section{Clinical characteristics and prognosis with atypical symptom}

In NRMI-2 report, patients with atypical presentation had a longer delay before hospital seek (mean, 7.9 vs. 5.3 hours), were less likely to be diagnosed with a myocardial infarction on admission ( $22 \%$ vs. $50 \%$ ), and were less likely to be treated with optimal medical therapy [aspirin $(60 \%$ vs. $85 \%), \beta$-blocker $(28 \%$ vs. $48 \%)$, heparin $(53 \%$ vs. $83 \%)$ ] and to receive thrombolytic therapy or primary percutaneous coronary intervention $(25 \%$ vs. $74 \%){ }^{6}$ Its results were similar with GRACE report. Not surprisingly, in-hospital mortality rates were much higher in patients with atypical presentation in both registry data (NRMI-2, 23\% vs. 9\%; GRACE 13\% vs. $4 \%$ ). Moreover, in-hospital complications were developed more in atypical presentation group. 


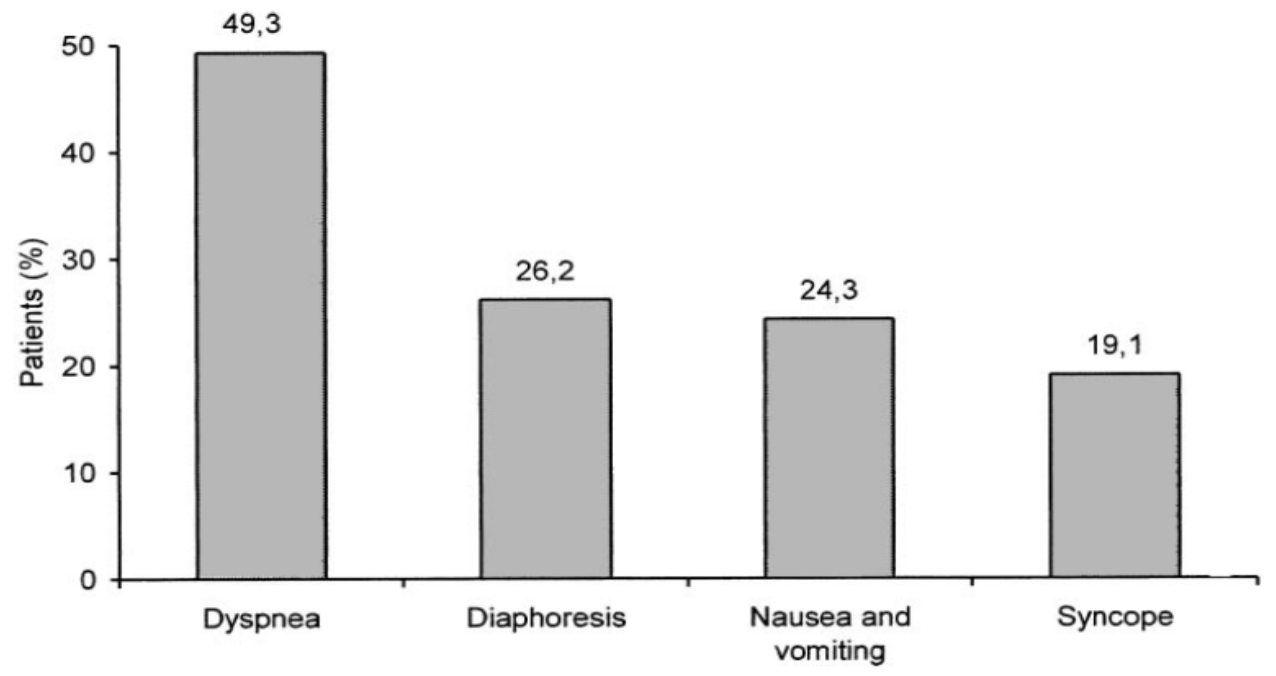

Fig. 2. Dominant symptom among patients with atypical presentation (Adopted from Brieger D, et al. Chest. 2004;126: 461-9)

\section{Risk factors of atypical presentation}

In NRMI-2 registry, Variables such as older age, gender, race, and co-morbidities (diabetes, stroke, heart failure) were considered as a risk factor for atypical symptom (Table.1), and many studies have described the association of aging, gender, and diabetes mellitus.

\begin{tabular}{ll}
\hline Variables & Odds Ratio (95\% confidential interval) \\
\hline Nonwhite & $1.05(1.03-1.07)$ \\
Women & $1.06(1.04-1.08)$ \\
Diabetes mellitus & $1.21(1.19-1.23)$ \\
Age (10-year interval) & $1.28(1.26-1.28)$ \\
Prior stroke & $1.43(1.40-1.47)$ \\
Prior heart failure & $1.77(1.74-1.81)$ \\
\hline
\end{tabular}

Table 1. Independent risk factor for atypical presentation (Adopted from Canto J.G, et al. JAMA. 2000;283:3223-9) 


\subsection{Women}

Atypical presentation in ACS was observed more commonly in women than men in large cohort studies (Table 2). Women with coronary heart disease are older by 10 years and have more risk factors than men. It might be due to lack of early recognition and management.

There are several differences between men and women in presentation. Women were less likely to have typical angina, rated their pain as more intense, used different words to describe it (more burning, sharp), and reported more non-pain-related symptoms than men. They experienced pain and other sensations in the neck area more frequently. Another feature of chest pain in women is that angina being induced by rest, sleep, mental stress instead of or addition to physical exertion. Psychosocial factors might also affect symptom presentation and diagnostic approach in women. For example, a history of anxiety disorders is associated with a lower probability of significant angiographic disease among women with chest pain symptoms. As women underestimate their own risk of coronary artery disease, diagnostic approach by physician could be altered less aggressively than men. Compared with men, women are less likely to perform cardiac monitoring, cardiac enzyme measurement, electrocardiogram, cardiac consultation, admission to a coronary care unit, undergo less coronary angiography, angioplasty, and bypass surgery.

\begin{tabular}{lcccc}
\hline \multirow{1}{*}{ Study name } & Study years & Sample size & \multicolumn{2}{c}{ Atypical symptom (\%) } \\
\cline { 4 - 5 } & & & Men & Women \\
\hline GRACE & $1999-2002$ & 20881 & 7.3 & 10.6 \\
NRMI-2 & $1994-1998$ & 434877 & 28.6 & 38.6 \\
Alabama UA registry & $1993-1999$ & 4167 & 50.2 & 53.0 \\
United kingdom & 1995 & 2096 & 17.6 & 24.6 \\
Worcester MI study & $1986-1988$ & 1360 & 18.0 & 23.0 \\
Worcester MI study & $1997-1999$ & 2073 & 30.9 & 45.8 \\
26 hospitals, CCU Israel & 2000 & 2113 & 18.7 & 29.7 \\
Croatia & $1990-1995$ & 1996 & 12.4 & 20.3 \\
Olmsted County & $1985-1992$ & 2271 & 25.0 & 19.0 \\
\hline Cumulative & & & 27.4 & 37.5 \\
\hline
\end{tabular}

Table 2. Prevalence of atypical presentation in large cohort 


\subsection{Diabetes mellitus}

Some patients with diabetes mellitus (DM) have a blunted perception of ischemic chest pain, which could result in atypical presentation. The suggested mechanisms of this phenomenon are as follows; 1) autonomic neuropathy, 2) prolongation of the anginal perceptual threshold.

Sympathetic denervation diabetic patients have evidence of a significant reduction in MIBG uptake, most likely on the basis of autonomic dysfunction. Furthermore, diabetic patients with silent myocardial ischemia have evidence of a diffuse abnormality in metaiodobenzylguanidine (MIBG) uptake, suggesting that abnormalities in pain perception may be linked to sympathetic denervation. Similar finding has also been observed with positron emission tomography. Moreover, regional heterogeneity in sympathetic denervation could result in potentially life-threatening myocardial electrical instability that may lead to life-threatening arrhythmias.

Another mechanism of abnormal perception is prolongation of the angina perceptual threshold during exercise. Anginal perceptual threshold (the time from onset of $0.1 \mathrm{mV}$ of ST segment depression to onset of angina during treadmill exercise) is prolonged in diabetic patients with coronary artery disease. The permissive effect of a prolonged anginal perceptual threshold on exercise capacity is undesirable as reflected by its correlation with ischemia at peak exercise $(r=0.6$, $p$ less than 0.001$)$ : the longer the threshold, the greater the exercise capacity and the more severe the ischemia.

\subsection{Age and atypical presentation}

Advanced age is an important predictor of atypical presentation and poor prognosis. Recent study in Korea examined and compared the risk factor associated with atypical presentation according to the age parameter. In this study, diabetes and hyperlipidemia significantly predicted atypical symptom in relatively young ( $<70$ years) age group. Otherwise, comorbid conditions such as stroke or chronic obstructive pulmonary disease were the positive predictors in relatively old age group (>70 years) (Table 3 ).

\begin{tabular}{lllll}
\hline & $\begin{array}{l}\text { Younger }(\mathrm{n}=49) \\
\text { Adjust OR (95\% CI) }\end{array}$ & $\mathrm{P}$ & $\begin{array}{l}\text { Older }(\mathrm{n}=41) \\
\text { Adjust OR (95\% CI) }\end{array}$ & $\mathrm{P}$ \\
\hline Female gender & $0.861(0.576-1.769)$ & 0.069 & $0.721(0.780-2.599)$ & 0.385 \\
Hypertension & $0.740(0.712-1.875)$ & 0.352 & $0.628(0.780-2.599)$ & 0.208 \\
Diabetes & $2.494(1.108-4.014)$ & 0.023 & $0.841(0.416-1.515)$ & 0.719 \\
Hyperlipidemia & $0.486(0.285-0.828)$ & 0.006 & $0.840(0.438-1.611)$ & 0.465 \\
Co-morbidity & $2.029(0.889-4.633)$ & 0.093 & $3.315(1.357-8.729)$ & 0.001 \\
Smoking & $0.595(0.345-1.025)$ & 0.061 & $0.575(0.255-1.297)$ & 0.157 \\
ACS type & $1.243(0.675-1.235)$ & 0.883 & $1.041(0.744-1.417)$ & 0.877 \\
Constant & 0.162 & $<0.001$ & 0.258 & 0.001 \\
\hline
\end{tabular}

Table 3. Predicting factors on atypical presentation in younger and older patients (Adopted from Hwang S.Y, et al. J Korean Med Sci. 2009;24:789-94)

\section{Conclusions}

ACS patients with atypical presentation are under-diagnosed and under-treated high risk group. Several clinical risk factors could be helpful in prediction of ACS in this group. 
Health care providers should have more concerns about the presence of ACS in patients who have these risk factors.

\section{References}

Panju A.A., Hemmelgarn B.R., Guyatt G.H., Simel D.L. (1998). The rational clinical examination. Is this patient having a myocardial infarction? JAMA, 280, 1256-1263.

Swap C.J., Nagurney J.T. (2005). Value and limitations of chest pain history in the evaluation of patients with suspected acute coronary syndromes. JAMA, 294, 2623-2629.

Servi R.J., Skiendzielewski J.J. (1985). Relief of myocardial ischemia pain with a gastrointestinal cocktail. Am J Emerg Med, 3, 208-209.

Henrikson C.A., Howell E.E., Bush D.E., et al. (2003). Chest pain relief by nitroglycerin does not predict active coronary artery disease. Ann Intern Med, 139, 979-986.

Brieger D., Eagle K.A., Goodman S.G., et al. GRACE Investigators. (2004). Acute coronary syndromes without chest pain, an underdiagnosed and undertreated high-risk group: insights from the Global Registry of Acute Coronary Events. Chest, 126, 461469.

Canto J.G., Shlipak M.G., Rogers W.J., et al. (2000). Prevalence, clinical characteristics, and mortality among patients with myocardial infarction presenting without chest pain. JAMA, 283, 3223-3229.

Gregoratos G. (2001). Clinical manifestations of acute myocardial infarction in older patients. Am J Geriatr Cardiol, 10, 345-347.

Patel H., Rosengren A., Ekman I. (2004). Symptoms in acute coronary syndromes: does sex make a difference? Am Heart J, 148, 27-33.

Arslanian-Engoren C., Patel A., Fang J., Armstrong D., et al. (2006). Symptoms of men and women presenting with acute coronary syndromes. Am J Cardiol. 2006, 98, 11771181.

DeVon H.A., Ryan C.J., Ochs A.L., Shapiro M. (2008). Symptoms across the continuum of acute coronary syndromes: differences between women and men. Am J Crit Care, 17, 14-24; quiz 25.

Canto J.G., Goldberg R.J., Hand M.M., Bonow R.O., Sopko G., Pepine C.J., Long T. (2007). Symptom presentation of women with acute coronary syndromes: myth vs reality. Arch Intern Med,167, 2405-2413.

Lerner D.J., Kannel W.B. (1986). Patterns of coronary heart disease morbidity and mortality in the sexes: a 26-year follow-up of the Framingham population. Am Heart J, 111, 383-390.

Kannel W.B., Vokonas P.S. (1992). Demographics of the prevalence, incidence, and management of coronary heart disease in the elderly and in women. Ann Epidemiol, 2, 5-14.

Stangl V., Witzel V., Baumann G., Stangl K. (2008). Current diagnostic concepts to detect coronary artery disease in women. Eur Heart J, 29, 707-717.

Alexander K.P., Shaw L.J., Shaw L.K., Delong E.R., Mark D.B., Peterson E.D. (1998). Value of exercise treadmill testing in women. J Am Coll Cardiol, 32, 1657-1664. 
D'Antono B., Dupuis G., Fortin C., Arsenault A., Burelle D. (2006). Angina symptoms in men and women with stable coronary artery disease and evidence of exercise-induced myocardial perfusion defects. Am Heart J, 151, 813-819.

Pepine C.J., Abrams J., Marks R.G., Morris J.J., Scheidt S.S., Handberg E. (1994). Characteristics of a contemporary population with angina pectoris. TIDES Investigators. Am J Cardiol, 74, 226-231.

Rutledge T., Reis S.E., Olson M., et al. Women's Ischemia Syndrome Evaluation (WISE). (2001). History of anxiety disorders is associated with a decreased likelihood of angiographic coronary artery disease in women with chest pain: the WISE study. J Am Coll Cardiol, 37, 780-785.

Birdwell B.G., Herbers J.E., Kroenke K. (1993). Evaluating chest pain. The patient's presentation style alters the physician's diagnostic approach. Arch Intern Med, 153, 1991-1995.

Lehmann J.B., Wehner P.S., Lehmann C.U., Savory L.M. (1996). Gender bias in the evaluation of chest pain in the emergency department. Am J Cardiol, 77, 641644.

Anand S.S., Xie C.C., Mehta S., et al. CURE Investigators. (2005). Differences in the management and prognosis of women and men who suffer from acute coronary syndromes. J Am Coll Cardiol, 46, 1845-1851.

Yu H.T., Kim K.J., Bang W.D., et al. (2011). Gender-based differences in the management and prognosis of acute coronary syndrome in Korea. Yonsei Med J, 52, 562-568.

Langer A., Freeman M.R., Josse R.G., Armstrong P.W. (1995). Metaiodobenzylbenzolguanidine imaging in diabetes mellitus: assessment of cardiac sympathetic denervation and its relation to autonomic dysfunction and silent myocardial ischemia. J Am Coll Cardiol, 25, 610-618.

Di Carli M.F., Bianco-Batlles D., Landa M.E., et al. (1999). Effects of autonomic neuropathy on coronary blood flow in patients with diabetes mellitus. Circulation, 100, 813819.

Stevens M.J., Raffel D.M., Allman K.C., et al. (1998). Cardiac sympathetic dysinnervation in diabetes: implications for enhanced cardiovascular risk. Circulation, 98, 961968.

Ranjadayalan K., Umachandran V., Ambepityia G., Kopelman P.G., Mills P.G., Timmis A.D. (1990). Prolonged anginal perceptual threshold in diabetes: effects on exercise capacity and myocardial ischemia. J Am Coll Cardiol, 16, 1120-1124.

Stern S., Behar S., Leor J., Harpaz D., Boyko V., Gottlieb S. Israeli Working Group on Intensive Cardiac Care, Israel Heart Society. (2004). Presenting symptoms, admission electrocardiogram, management, and prognosis in acute coronary syndromes: differences by age. Am J Geriatr Cardiol, 13, 188-96.

Calle P., Jordaens L., De Buyzere M., Rubbens L., Lambrecht B., Clement D.L. (1994). Agerelated differences in presentation, treatment and outcome of acute myocardial infarction. Cardiology, 85, 111-20. 
Hwang S.Y., Park E.H., Shin E.S., Jeong M.H. (2009). Comparison of factors associated with atypical symptoms in younger and older patients with acute coronary syndromes. J Korean Med Sci, 24, 789-94. .

Hwang S.Y., Jeong M.H. (2010). Cognitive factors that influence delayed decision to seek treatment among older patients with acute myocardial infarction in Korea. Eur J Cardiovasc Nurs, in-press.

Hwang S.Y., Zerwic J.J., Jeong M.H. (2011). Impact of prodromal symptoms on prehospital delay in patients with first-time acute myocardial infarction in Korea. J Cardiovasc Nurs, 26, 194-201. 


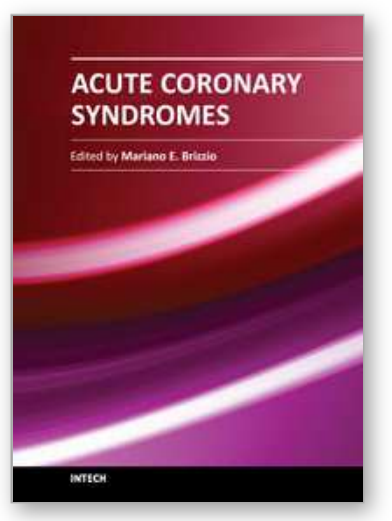

\author{
Acute Coronary Syndromes \\ Edited by Dr. Mariano Brizzio
}

ISBN 978-953-307-827-4

Hard cover, 214 pages

Publisher InTech

Published online 24, February, 2012

Published in print edition February, 2012

This book has been written with the intention of providing an up-to-the minute review of acute coronary syndromes. Atherosclerotic coronary disease is still a leading cause of death within developed countries and not surprisingly, is significantly rising in others. Over the past decade the treatment of these syndromes has changed dramatically. The introduction of novel therapies has impacted the outcomes and surviving rates in such a way that the medical community need to be up to date almost on a "daily bases". It is hoped that this book will provide a timely update on acute coronary syndromes and prove to be an invaluable resource for practitioners seeking new and innovative ways to deliver the best possible care to their patients.

\title{
How to reference
}

In order to correctly reference this scholarly work, feel free to copy and paste the following:

Hyun Kuk Kim and Myung Ho Jeong (2012). Atypical Presentation in Patients with Acute Coronary Syndrome, Acute Coronary Syndromes, Dr. Mariano Brizzio (Ed.), ISBN: 978-953-307-827-4, InTech, Available from: http://www.intechopen.com/books/acute-coronary-syndromes/atypical-symptoms-of-acute-coronary-syndrome

\section{INTECH}

open science | open minds

\section{InTech Europe}

University Campus STeP Ri

Slavka Krautzeka 83/A

51000 Rijeka, Croatia

Phone: +385 (51) 770447

Fax: +385 (51) 686166

www.intechopen.com

\section{InTech China}

Unit 405, Office Block, Hotel Equatorial Shanghai

No.65, Yan An Road (West), Shanghai, 200040, China

中国上海市延安西路65号上海国际贵都大饭店办公楼 405 单元

Phone: +86-21-62489820

Fax: $+86-21-62489821$ 
(C) 2012 The Author(s). Licensee IntechOpen. This is an open access article distributed under the terms of the Creative Commons Attribution 3.0 License, which permits unrestricted use, distribution, and reproduction in any medium, provided the original work is properly cited. 